\title{
UNEMPLOYMENT AND SELF-ASSESSED HEALTH: EVIDENCE FROM PANEL DATA
}

\author{
PETRI BÖCKERMAN ${ }^{\mathrm{a}, *}$ and PEKKA ILMAKUNNAS ${ }^{\mathrm{b}}$ \\ ${ }^{\text {a }}$ Labour Institute for Economic Research, Helsinki, Finland \\ ${ }^{\mathrm{b}}$ Helsinki School of Economics and HECER, Helsinki, Finland
}

\begin{abstract}
SUMMARY
We examine the relationship between unemployment and self-assessed health using the European Community Household Panel for Finland over the period 1996-2001. Our results show that the event of becoming unemployed does not matter as such for self-assessed health. The health status of those that end up being unemployed is lower than that of the continually employed. Therefore, persons who have poor health are being selected for the pool of the unemployed. This explains why, in a cross-section, unemployment is associated with poor self-assessed health. All in all, the cross-sectional negative relationship between unemployment and self-assessed health is not found longitudinally. Copyright (C) 2008 John Wiley \& Sons, Ltd.
\end{abstract}

Received 21 August 2007; Revised 14 March 2008; Accepted 19 March 2008

JEL classification: $\mathrm{C} 23$; $\mathrm{I} 10$

KEY WORDS: unemployment; well-being; self-assessed health; panel data; ECHP

\section{INTRODUCTION}

The welfare effects of unemployment have been examined in many strands of research. Several studies ranging from research papers in medicine to those in the social sciences and economics have shown that unemployment is associated with adverse health outcomes (e.g. Björklund and Eriksson, 1998; Mathers and Schofield, 1998). Both cross-sectional and panel data sets and both objective and subjective measures of health have been used in the literature. ${ }^{1}$ In particular, the unemployed are unhappy if they are evaluated by standard subjective measures (e.g. Clark and Oswald, 1994; Di Tella et al., 2001). There are studies that have looked at unemployment and the subsequent evolution of the subjective measures of well-being, most notably happiness and life satisfaction, in a panel data setting (e.g. Lucas et al., 2004; Clark, 2007; Clark et al., 2008), but the available evidence is still sparse in this respect. Furthermore, it has been shown that poor health is associated with subsequent unemployment (e.g. Arrow, 1996; Riphahn, 1999).

In this paper, our purpose is to examine the evolution of self-assessed health $(\mathrm{SAH})$ in a panel data setting before and after the event of unemployment occurs and also when unemployed persons become employed again in order to disentangle the causal effect of unemployment on health. In contrast to most of the earlier studies, we apply difference-in-differences models and matching methods. In particular,

\footnotetext{
*Correspondence to: Labour Institute for Economic Research, Pitkänsillanranta 3A, 6th floor, FI-00530 Helsinki, Finland. E-mail: petri.bockerman@labour.fi

${ }^{1}$ For example, Björklund (1985) provides an early application that uses panel data to study the effect of unemployment on mental health.
} 
the use of matching methods allows us to take into account the selection for unemployment and the possibility of reverse causality from poor health to unemployment. Previously, this selectivity issue had mainly been tackled by using plant closings as instruments for unemployment (e.g. Kuhn et al., 2004; Browning et al., 2006).

The most important empirical finding for the country under study, Finland, is that the event of unemployment does not matter as such for SAH in a panel data setting. The health status of those that end up being unemployed is lower than that of the continually employed before their unemployment episodes actually start. Hence, persons who have poor health are being selected for the pool of the unemployed. This explains why, in a cross-section, unemployment is associated with poor SAH, whereas in longitudinal data this negative relationship is not found.

We take advantage of the European Community Household Panel (ECHP) for Finland, which is a representative household survey. The ECHP has not been much exploited in the literature on the determination of SAH (see, however, Ahn et al., 2004; Cantarero and Pascual, 2005; Hildebrand and van Kerm, 2005; Economou et al., 2007; Etienne et al., 2007). The data cover a period long enough for reliable results about the adverse effects of unemployment on health to be obtained. It is useful to provide a detailed analysis of one country, because McFadden et al. (2005), among others, argue that the key problem with the questions on subjective well-being is that different respondents may interpret the response scales differently. This is most likely to be a severe problem in pooled cross-country comparisons of subjective well-being when one is using data sources such as the ECHP. For example, Kristensen and Johansson (2008) show that people in different European countries perceive job satisfaction differently. In a one-country study this problem is reduced.

The effect of unemployment on a subjective measure of health is interesting in the Finnish context for several reasons. First, the national unemployment rate surged very rapidly from 3 to $17 \%$ in the early 1990 s. $^{2}$ Such an increase has been unprecedented among the industrial countries. This may dilute the effect of unemployment on health, because less stress and social stigma may arise from being unemployed in times of high unemployment (e.g. Lindbeck et al., 1999; Clark, 2003). An opposite view is taken by Ahn et al. (2004), who argue that the smaller effects of unemployment on satisfaction with the main activity are observed in Denmark and the Netherlands, because unemployment is low in those two countries. Second, a relatively high unemployment rate that has persisted in Finland since the early 1990s is useful when one is investigating the relationship between unemployment and health. There are a great number of unemployment episodes that start at any given point of time that allow us to examine the causal effect of unemployment on health in detail. Furthermore, long-term unemployment rose a great deal in Finland during the 1990s. This is useful when investigating the habituation effects on unemployment. ${ }^{3}$ Third, there is earlier evidence according to which the relationship between unemployment and subjective well-being is rather weak in Finland (Böckerman and Ilmakunnas, 2006; Ervasti and Venetoklis, 2006). This available evidence uses cross-sectional data, however. Therefore, it is particularly interesting to see how this relationship manifests itself in a panel data setting where it is possible to isolate the underlying causal effect of unemployment on subjective well-being.

\footnotetext{
${ }^{2}$ Koskela and Uusitalo (2006) provide an overview of the Finnish unemployment problem. The average rate of unemployment in Finland was around $5 \%$ in the 1980 s before the recession. After the recession, the unemployment rate declined from 14.6 to $9.1 \%$ over the period 1996-2001. Therefore, the unemployment problem has been historically exceptional over our whole data period 1996-2001, and it is difficult to segment the period to examine the effects of becoming unemployed separately in periods of low and high aggregate unemployment rates.

${ }^{3}$ There are earlier Finnish studies on the health aspects of unemployment. The results based on the simple comparison of population averages are, for the most part, mixed (e.g. Martikainen and Valkonen, 1996; Lahelma et al., 1997). Jäntti et al. (2000) discover that regional unemployment has not been associated with mortality among Finns. The studies that use panel data are based on restricted samples covering special groups of workers (Lahelma, 1989; Leino-Arjas et al., 1999; Nyman, 2002). This makes it rather difficult to generalize the results obtained. Martikainen et al. (2007) report that workplace downsizing and workplace closures increase mortality among the affected workers, but the effects are modest in the context of high unemployment or rapid downsizing.
} 
Measures of SAH are widely used in empirical research. Despite this, there is still some amount of scepticism regarding the use of self-reported data on health. In particular, subjective measures of health that often originate from household surveys can be criticized on the grounds that they provide potentially biased information about persons' health for the very reason that they are self-reported. Accordingly, self-reported information on health cannot be as reliable as that based on objective measurement of health. However, various subjective measures of health have been proven to have substantial value in predicting objective health outcomes, including morbidity and mortality (e.g. Idler and Benyamini, 1997; Franks et al., 2003; Van Doorslaer and Jones, 2003). ${ }^{4}$ For that reason alone they are worth analysing.

\section{DATA}

Our paper takes advantage of the ECHP for Finland over the period 1996-2001. ${ }^{5}$ The ECHP is based on a standardized questionnaire that involves annual interviews of a representative panel of households and individuals in each European Union (EU) country (e.g. Peracchi, 2002). The fact that the ECHP is representative of the population is an important advantage with respect to some earlier studies on the relationship between unemployment and health that have used panel data sources. The ECHP is composed of a separate personal file and a separate household file that can be linked with each other. In this paper, we use data from the personal file, because it is the file that contains information on SAH.

The ECHP's questions include various topics such as income, health, education, housing, living conditions, demographics and employment characteristics, among other things. The ECHP data allow us to record the health status of individuals before their unemployment episodes actually start. This constitutes an important advantage over cross-section data sources that have been more frequently used in research to compare population averages, because we are in a better position to examine the causal effect of unemployment on health.

One's SAH status is an answer to the question (PH001): 'How is your health in general'?. This question aims to summarize an individual's general state of health at the moment of interview. SAH is measured on an ordinal 5-point Likert scale with alternatives 5 ('very good'), 4 ('good'), 3 ('fair'), 2 ('bad') or 1 ('very bad'). Hence, a higher value on this scale means that a person currently feels healthier. (We have reversed the scale of the health measure in the ECHP survey to emphasize that higher numbers correspond to better health.) A similar question on SAH appears in many other well-known household surveys such as the British Household Panel Survey and the German Socio-Economic Panel.

There is earlier research that has studied the determination of SAH by using the ECHP. Hildebrand and Van Kerm (2005) and Etienne et al. (2007) focus on the connection between income inequality and SAH by using the ECHP for several countries. Cantarero and Pascual (2005) investigate the relationship between socio-economic status and health by using the ECHP for Spain. Furthermore, Ahn et al. (2004) have reported that unemployment tends to be negatively related to SAH by using data on all countries in the ECHP, and Economou et al. (2007) use the number and the duration of past unemployment spells to examine the effect of unemployment experience on SAH.

In this paper, we focus on transitions between work and unemployment or vice versa. We include in the analyses those of working age that belong to the labour force. To be included in the sample, an individual has to be at least once unemployed or employed over the period 1996-2001. In particular, an individual who experiences a spell out of the labour force after experiencing an episode of unemployment is not automatically removed from the sample. However, we do not examine

\footnotetext{
${ }^{4}$ Crossley and Kennedy (2002) show that the response reliability of SAH is related to age, income and occupation. In total, around $28 \%$ of those that responded twice to the same health question changed their response regarding SAH.

${ }^{5}$ Finland was included in the ECHP for the first time in 1996 after she joined the European Union. The European Union stopped gathering data for the ECHP in 2001, which means that we have six waves of the data.
} 
transitions from other labour market states to inactivity or vice versa. The reference group of analyses consists of those that are continually at work. This means that unemployed persons are compared with persons with a strong attachment to the labour market.

The ECHP does not incorporate direct information about the unemployment duration for the persons interviewed. However, the data record monthly activity statuses (unemployed being one possible alternative) for each person for the whole year before the interview. In addition, the data contain information on the month in which the interview took place in each wave. This piece of information is important, because the main month of interview in the ECHP for Finland has changed from the beginning of the year in the first waves towards the end of the year in the last waves. By combining information on the monthly activity statuses and the month of interview, it is possible to construct a measure for each person's unemployment duration in months at the time of the interview. We define the term 'long-term unemployed' to include those persons who have been unemployed continuously for at least 6 months. In this way, we avoid the problem of 'top-coding' in the unemployment duration mentioned, in the context of the ECHP, by Clark (2007). ${ }^{6}$

\section{FINDINGS}

\subsection{Descriptive evidence}

Table I reports a cross-tabulation of the SAH and unemployment status. The data provide evidence that the health status of those who are currently unemployed is lower than that of the employed. In particular, long-term unemployment seems to damage SAH. However, a descriptive analysis that exploits solely the cross-sectional variation in the data is not able to reveal the causal relationship between unemployment and health.

To shed light on the causal relationship, we need to take advantage of the panel dimension of the ECHP. The Galton squeeze diagrams can be used to illustrate changes in health and the tendency that the more extreme scores regress towards the mean over time (see Campbell and Kenny, 1999). Our diagrams summarize the changes in health using all 2-year pairs in the panel over the period 1996-2001. The points on the left-hand side are the SAH levels for individuals in their first year of the 2-year period. Each initial health level is connected with a line to the average health score of the same individuals in the second year of the period, i.e. the first year health is used for predicting the second year health.

We present four Galton squeeze diagrams that are shown in different panels in Figure 1. We start by illustrating the changes in health around the beginning of unemployment episodes in the upper left-hand panel of Figure 1. The starting points of the lines on the left-hand side of the diagram show the initial levels of health while the individuals were still employed. The end-points of the lines on the right-hand side show the average level of health after becoming unemployed. For example, those who had SAH equal to 1 while still working had, on average, level 1.5 after becoming unemployed. On the other hand, those who had $\mathrm{SAH}$ equal to 5 while still working had, on average, level 4.5 after becoming unemployed.

The main interest in the diagrams is, however, not in the individual lines (which are therefore not marked with different symbols), but in the overall pattern of the lines. It shows that there is a clear regression towards the mean: those with poor or good health tend to converge towards the overall average. If health levels were uncorrelated over time, the lines would be horizontal. On the other hand, the lines do not converge to a lower value of health, so becoming unemployed does not seem to lead to a clear fall in health.

\footnotetext{
${ }^{6}$ For instance, in the first wave of the ECHP from the year 1996, 'top-coding' means that it is not possible to observe unemployment durations of over 12 months.
} 
Table I. Distribution of the level of self-assessed health (SAH)

\begin{tabular}{|c|c|c|c|c|}
\hline SAH & Employed & Unemployed & Long-term unemployed & All (employed and unemployed) \\
\hline 1 & $\begin{array}{l}32 \\
(0.18)\end{array}$ & $\begin{array}{l}18 \\
(0.66)\end{array}$ & $\begin{array}{l}11 \\
(0.90)\end{array}$ & $\begin{array}{l}50 \\
(0.24)\end{array}$ \\
\hline 2 & $\begin{array}{l}339 \\
(1.89)\end{array}$ & $\begin{array}{l}143 \\
(5.28)\end{array}$ & $\begin{array}{l}83 \\
(6.83)\end{array}$ & $\begin{array}{l}482 \\
(2.34)\end{array}$ \\
\hline 3 & $\begin{array}{l}3779 \\
(21.12)\end{array}$ & $\begin{array}{l}771 \\
(28.46)\end{array}$ & $\begin{array}{l}439 \\
(36.10)\end{array}$ & $\begin{array}{l}4550 \\
(22.09)\end{array}$ \\
\hline 4 & $\begin{array}{l}9807 \\
(54.92)\end{array}$ & $\begin{array}{l}1296 \\
(47.84)\end{array}$ & $\begin{array}{l}522 \\
(42.93)\end{array}$ & $\begin{array}{l}11103 \\
(53.90)\end{array}$ \\
\hline 5 & $\begin{array}{l}3933 \\
(21.98)\end{array}$ & $\begin{array}{l}481 \\
(17.76)\end{array}$ & $\begin{array}{l}162 \\
(13.24)\end{array}$ & $\begin{array}{l}4414 \\
\quad(21.43)\end{array}$ \\
\hline Total & $\begin{array}{r}17890 \\
(100)\end{array}$ & $\begin{array}{l}2709 \\
(100)\end{array}$ & $\begin{array}{l}1216 \\
(100)\end{array}$ & $\begin{array}{r}20599 \\
(100)\end{array}$ \\
\hline
\end{tabular}

Note: Percentage shares of column totals in parentheses. Long-term unemployed are those who have been unemployed continuously at least for 6 months.
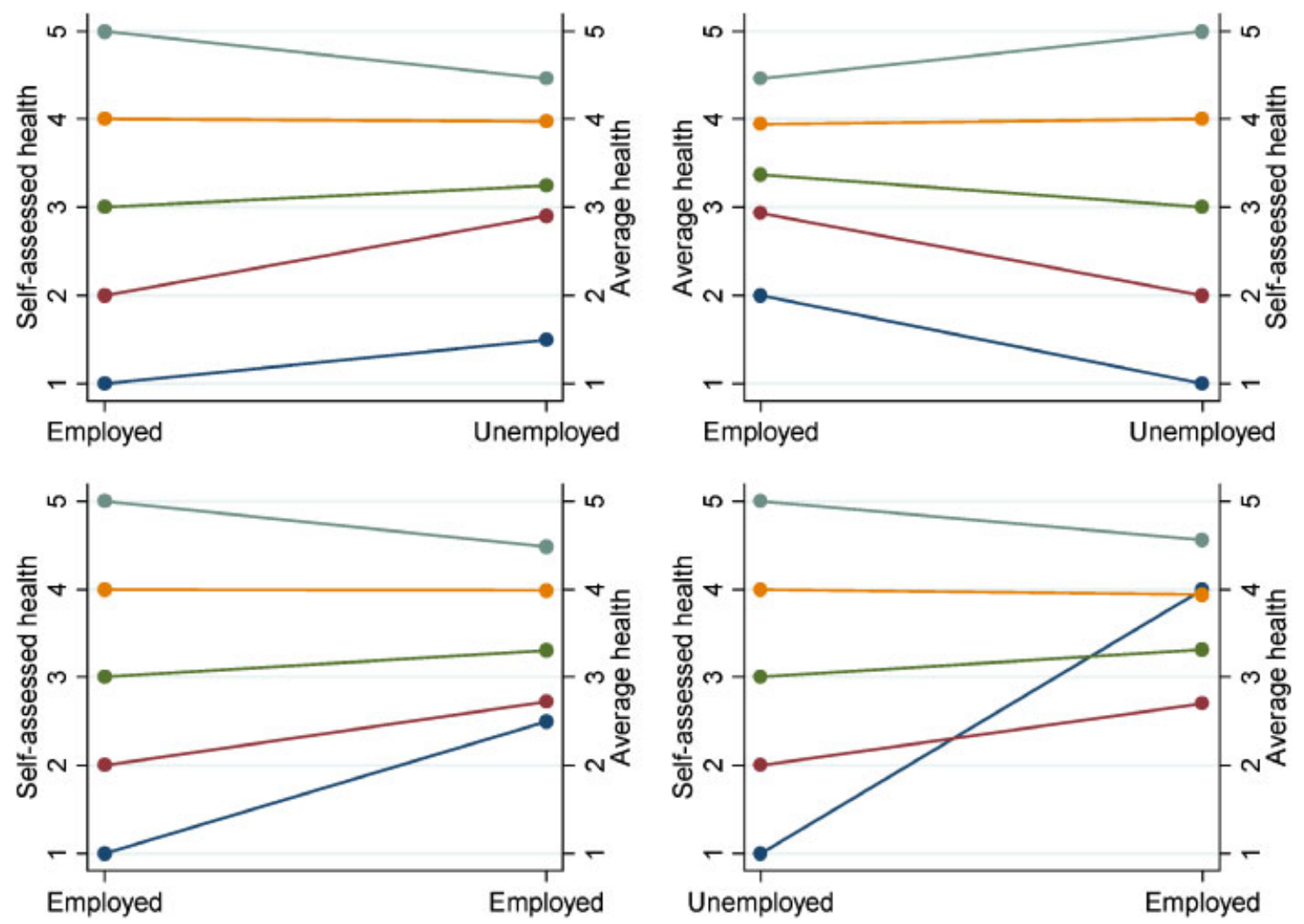

Figure 1. Galton squeeze diagrams

The upper right-hand panel of Figure 1 shows a time-reversed Galton squeeze diagram where the end-point of each line in the right-hand side of the panel is the health level of unemployed persons and the starting point is their average health level while the same persons were still employed. That is, we use 
health while unemployed to predict pre-unemployment health. For example, those who have health equal to 5 after becoming unemployed had, on average, health level 4.5 while still working. Those with extreme values of the health score were closer to the overall mean previously - regression towards the mean also works backwards in time.

The lower left-hand panel of Figure 1 shows the diagram drawn using data from all 2-year periods where the individuals were employed in both years. We can see that even in this case there is a regression towards the mean. The main difference between the upper left-hand panel and the lower left-hand panel is that those who have low SAH in the first period in the upper left-hand panel do not converge as much to the average as those with low health in the lower left-hand panel. That is, those with low health while employed tend to stay at a relatively low health level when they become unemployed. However, in general, we cannot say that those becoming unemployed converge to a different overall mean health level than those in continuous employment.

The relationship between health and unemployment can also be evaluated by looking at changes in SAH when a person switches from unemployment to employment. The lower right-hand panel of Figure 1 shows the Galton squeeze diagram for those who are unemployed in the first year, but employed in the second one. The pattern in this diagram is similar to the previous diagrams, except for the line starting from 1 , which is, however, based on only two observations. ${ }^{7}$

One problem clearly revealed by Figure 1 is that the regression towards the mean is partly driven by the fact that health cannot improve beyond level 5 and, hence, for those initially at level 5 , the level in the next year is likely to be on average below 5. Similarly, health cannot fall below level 1 and, hence, for those initially at level 1 , the level in the next year is likely to be on average above 1 . It is, therefore, likely that controlling for the initial level of health is necessary when one is studying changes in the health scores. ${ }^{8}$

\subsection{Difference-in-differences estimates}

To examine the relationship between unemployment and health more closely, we estimate difference-indifferences models in which an individual's SAH is explained with a dummy variable for the 'unemployment target group' that consists of persons that become unemployed at least once during the period 1996-2001, a dummy variable for those currently unemployed after a period of employment (the dummy is equal to one in all the years of unemployment after an employment spell), a dummy for the 'employment target group' that consists of those who become employed at least once, a dummy for those currently employed after a period of unemployment (the dummy is equal to one in all the years of employment after an unemployment spell), a dummy for those who are unemployed for the whole data period and year dummies to capture the effect of business cycle fluctuations. In some of the models we also include individual-level control variables $X$, age and its square, gender and the level of education in three categories, which capture the 'usual suspects' that should have a bearing on $\mathrm{SAH}^{9}$

We start by analysing changes in health status treating SAH as a cardinal measure and assuming that both experiencing unemployment and becoming employed after a period of unemployment are exogenous events. Below we also examine health as an ordinal variable, but the cardinal scale is a useful 'benchmark'. The results have an easy interpretation, and comparison with propensity score matching

\footnotetext{
${ }^{7}$ There are only two persons who were initially at health level 1. After becoming employed both of them were at level 4.

${ }^{8}$ See, for example, Henning et al. (2003) for a discussion on this issue in another context.

${ }^{9}$ For instance, it is a well-known fact that better educated persons are usually healthier both by subjective and objective measures (see Martikainen, 1995, for evidence from Finland). The three education categories in the ECHP are third-level education (ISCED 5-7), second stage of secondary level education (ISCED 3) and less than second stage of secondary level education (ISCED 0-2).
} 
Table II. Effect of labour market status on SAH

\begin{tabular}{|c|c|c|c|c|c|c|c|}
\hline & OLS & $\begin{array}{l}\text { Fixed } \\
\text { effects }\end{array}$ & $\begin{array}{l}\text { Ordered } \\
\text { logit }\end{array}$ & $\begin{array}{l}\text { Ordered } \\
\text { logit }\end{array}$ & $\begin{array}{c}\mathrm{FE} \\
\text { ordered } \\
\text { logit }\end{array}$ & $\begin{array}{c}\mathrm{FE} \\
\text { ordered } \\
\text { logit }\end{array}$ & $\begin{array}{c}\text { RE } \\
\text { ordered } \\
\text { probit }\end{array}$ \\
\hline $\begin{array}{l}\text { Becomes unemployed } \\
\text { at least once (BU) }\end{array}$ & $\begin{array}{l}-0.097 \\
(0.024)^{* * *}\end{array}$ & & $\begin{array}{l}-0.541 \\
(0.067)^{* * *}\end{array}$ & $\begin{array}{l}-0.273 \\
(0.067)^{* * *}\end{array}$ & & & $\begin{array}{l}-0.228 \\
(0.080)^{* * *}\end{array}$ \\
\hline Unemployed after & 0.028 & 0.032 & -0.076 & 0.067 & 0.198 & 0.199 & 0.073 \\
\hline employment (UE) & $(0.037)$ & $(0.029)$ & $(0.104)$ & $(0.105)$ & $(0.139)$ & $(0.139)$ & $(0.068)$ \\
\hline Becomes employed & 0.009 & & 0.262 & 0.032 & & & 0.012 \\
\hline at least once $(\mathrm{BE})$ & $(0.029)$ & & $(0.065)^{* * *}$ & $(0.066)$ & & & $(0.072)$ \\
\hline Employed after & -0.018 & -0.008 & -0.098 & -0.064 & 0.010 & 0.011 & -0.031 \\
\hline unemployment (EU) & $(0.029)$ & $(0.024)$ & $(0.083)$ & $(0.083)$ & $(0.115)$ & $(0.116)$ & $(0.059)$ \\
\hline $\begin{array}{l}\text { Always unemployed } \\
\text { (AU) }\end{array}$ & $\begin{array}{l}-0.263 \\
(0.027)^{* * *}\end{array}$ & & $\begin{array}{l}-1.150 \\
(0.071)^{* * *}\end{array}$ & $\begin{array}{l}-0.694 \\
(0.073)^{* * *}\end{array}$ & & & $\begin{array}{l}-0.558 \\
(0.093)^{* * *}\end{array}$ \\
\hline Year dummies & Yes & Yes & Yes & Yes & Yes & Yes & Yes \\
\hline Control variables & Yes & Yes & No & Yes & No & Yes & Yes \\
\hline$N$ & 19206 & 19206 & 19206 & 19206 & 12891 & 12891 & 19206 \\
\hline
\end{tabular}

Note: Robust standard errors in parentheses (except in Column 7). Significance: ${ }^{* * *} 1,{ }^{* *} 5,{ }^{*} 10 \%$. Reference group: continuously employed. Unreported control variables include age and its square, gender and the level of education in three categories. In the fixed effects models gender is excluded. In FE ordered logit age is also excluded. In the RE model, individual means of control variables are also included.

results, presented below, is straightforward. The estimated model is

$$
\begin{aligned}
\mathrm{SAH}_{i t}= & \alpha+\beta(\mathrm{BU})_{i}+\gamma(\mathrm{UE})_{i t}+\phi(\mathrm{BE})_{i}+\mu(\mathrm{EU})_{i t} \\
& +\eta(\mathrm{AU})_{i}+X_{i t} \theta+\Sigma_{t} \tau_{t}(\text { Year } t)+\epsilon_{i t}
\end{aligned}
$$

where SAH denotes 'self-assessed health', BU denotes 'becomes unemployed at least once', UE denotes 'unemployed after employment', BE denotes 'becomes employed at least once', EU denotes 'employed after unemployment' and AU means 'always unemployed'.

The average health level for the reference group, those in continuous employment, is $\alpha$, for those who become unemployed at some stage but are currently employed $\alpha+\beta$, for those who become unemployed $\alpha+\beta+\gamma$, for those who become employed at some stage but are currently unemployed $\alpha+\phi$, for those who become employed $\alpha+\phi+\mu$ and for those who are unemployed for the whole period $\alpha+\eta$. It is possible that some individuals become unemployed in some period and employed in some other period (or vice versa), so that they belong to both 'target groups'. For them, the 'basic' level of health is $\alpha+\beta+$ $\phi$ and it is changed by $\gamma(\mu)$ when they become unemployed (employed). The coefficients of the indicator variables are reported in the columns of Table II.

The results in Column 1 reveal that those who are always unemployed in the data period clearly have lower health (the indicator is significant at the $1 \%$ level), but also those who become unemployed at some stage have a lower SAH level. On the other hand, when those who are working become unemployed, their health does not deteriorate and when those who are unemployed find a job, their health status does not improve. Therefore, our results show that unemployment as such does not seem to worsen health. It is more the case that the persons who experience poor health are selected for the pool of unemployed persons. ${ }^{10}$

There may be unobserved attributes of the individuals that affect both the level of health experienced and the probability of being unemployed. This would lead to inconsistency of the ordinary least squares (OLS) estimates of the difference-in-differences model. To account for this, we estimate the model with

\footnotetext{
${ }^{10}$ When the control variables are not included, the indicator for those becoming employed at least once obtains a positive and significant coefficient. Those who manage to escape unemployment tend to have better health in the first place.
} 
Table III. Marginal effects of labour market status and past health on SAH

\begin{tabular}{|c|c|c|c|c|c|c|}
\hline & $\begin{array}{l}\text { Ordered logit, } \\
\operatorname{Pr}(\mathrm{SAH}=1)\end{array}$ & $\begin{array}{l}\text { Ordered logit, } \\
\operatorname{Pr}(\mathrm{SAH}=2)\end{array}$ & $\begin{array}{l}\text { Ordered logit, } \\
\operatorname{Pr}(\mathrm{SAH}=5)\end{array}$ & $\begin{array}{l}\text { Ordered logit, } \\
\operatorname{Pr}(\mathrm{SAH}=1)\end{array}$ & $\begin{array}{l}\text { Ordered logit, } \\
\operatorname{Pr}(\mathrm{SAH}=2)\end{array}$ & $\begin{array}{c}\text { Ordered logit, } \\
\operatorname{Pr}(\mathrm{SAH}=5)\end{array}$ \\
\hline $\begin{array}{l}\text { Becomes unemployed } \\
\text { at least once }(\mathrm{BU})\end{array}$ & $\begin{array}{l}0.00049 \\
(0.00015)^{* * *}\end{array}$ & $\begin{array}{l}0.00508 \\
(0.00140)^{* * *}\end{array}$ & $\begin{array}{l}-0.03796 \\
(0.00861)^{* * *}\end{array}$ & $\begin{array}{c}0.00008 \\
(0.00005)\end{array}$ & $\begin{array}{c}0.00099 \\
(0.00065)\end{array}$ & $\begin{array}{l}-0.01324 \\
(0.00791)^{*}\end{array}$ \\
\hline Unemployed after & -0.00010 & -0.00108 & 0.01019 & -0.00003 & -0.00035 & 0.00537 \\
\hline employment (UE) & $(0.00016)$ & $(0.00164)$ & $(0.01624)$ & $(0.00006)$ & $(0.00080)$ & $(0.01274)$ \\
\hline Becomes employed at & -0.00005 & -0.00052 & 0.00474 & -0.00006 & -0.00079 & 0.01252 \\
\hline least once (BE) & $(0.00010)$ & $(0.00107)$ & $(0.00994)$ & $(0.00005)$ & $(0.00058)$ & $(0.00981)$ \\
\hline Employed after & 0.00011 & 0.00110 & -0.00945 & 0.00009 & 0.00109 & -0.01441 \\
\hline unemployment (EU) & $(0.00014)$ & $(0.00146)$ & $(0.01197)$ & $(0.00007)$ & $(0.00083)$ & $(0.00981)$ \\
\hline Always unemployed & 0.00154 & 0.01590 & -0.08395 & 0.00027 & 0.00339 & -0.03586 \\
\hline$(\mathrm{AU})$ & $(0.00032)^{* * *}$ & $(0.00236)^{* * *}$ & $(0.00703)^{* *}$ & $(0.00009)^{* * *}$ & $(0.00093)^{* * *}$ & $(0.00700)^{* * *}$ \\
\hline \multirow[t]{2}{*}{$\mathrm{SAH}(t-1)=2$} & & & & -0.00020 & -0.00251 & 0.05272 \\
\hline & & & & $(0.00016)$ & $(0.00199)$ & $(0.05940)$ \\
\hline $\mathrm{SAH}(t-1)=3$ & & & & -0.00084 & -0.01055 & 0.37347 \\
\hline & & & & $(0.00018)^{* * *}$ & $(0.00153)^{* * *}$ & $(0.08605)^{* * *}$ \\
\hline $\mathrm{SAH}(t-1)=4$ & & & & -0.00590 & -0.06923 & 0.48863 \\
\hline & & & & $(0.00162)^{* * *}$ & $(0.01472)^{* * *}$ & $(0.05059)^{* * *}$ \\
\hline $\mathrm{SAH}(t-1)=5$ & & & & -0.00216 & $\begin{array}{l}-0.02669 \\
(0.00275) * * *\end{array}$ & 0.91081 \\
\hline Year dummies & Yes & Yes & Yes & Yes & Yes & Yes \\
\hline Control variables & Yes & Yes & Yes & Yes & Yes & Yes \\
\hline
\end{tabular}

Note: Columns 1-3 report the marginal effects for the probabilities (differences in probabilities) of the outcomes 1,2 and 5 from the model that is shown in Column 4 of Table II. Columns 4-6 report the marginal effects from the model in Column 4 of Table IV. Robust standard errors in parentheses. Significance: ${ }^{* * * *} 1,{ }^{* *} 5,{ }^{*} 10 \%$. Reference group: continuously employed. Unreported control variables include age and its square, gender and the level of education in three categories.

fixed effects using the within transformation. ${ }^{11}$ In this case, the time-invariant group indicators are left out (and the gender dummy is excluded from the controls). The estimated model is

$$
\mathrm{SAH}_{i t}=\alpha_{i}+\gamma(\mathrm{UE})_{i t}+\mu(\mathrm{EU})_{i t}+X_{i t} \theta+\Sigma_{t} \tau_{t}(\text { Year } t)+\epsilon_{i t}
$$

The results without lagged health are shown in Column 2 of Table II. Again, the indicators for being unemployed after employment and for being employed after unemployment are not statistically significant. Hence, there is no clear impact of unemployment on health.

The above benchmark results are based on treatment of the health scores as cardinal variables. It is likely, however, that the respondents do not treat health level 3, for example, as three times as good as level 1. Therefore, it is important to estimate the difference-in-differences model (1) using an ordered response model. In this case we assume that $\mathrm{SAH}$ is a continuous latent variable that is observed as a discrete ordinal variable. The ordered logit results are shown in Columns 3 (without controls) and 4 (with controls) of Table II. The results regarding the signs and significance of the coefficients are quite similar to those obtained with the OLS estimation, although the magnitudes of the coefficients are, of course, not comparable.

We report the marginal effects for the probabilities of the best and worst health outcomes from the ordered logit models in Table III (Columns 1-3). Since the number of individuals with a health score equal to 1 is relatively small, we present the marginal effects for scores 1,2 and 5 . We report only the results for the indicator variables, for which the marginal effects are calculated as differences in probabilities. These marginal effects provide a similar qualitative picture of the effects as the coefficients in Table II. The marginal effects for the probabilities of the lowest outcomes, 1 and 2, are very small, but show that those who are always unemployed or become unemployed at some stage have a higher

\footnotetext{
${ }^{11}$ The problem with this approach is that if SAH contains a lot of measurement error as argued by Crossley and Kennedy (2002), taking the within transformation of the data may worsen the signal-to-noise ratio substantially.
} 
probability to have low health. For the outcome 5, the marginal effects are more substantial. For example, Column 3 of Table III reveals that those who have always been unemployed over the period 1996-2001 are 8.4\% less likely to report that their health level is 5, other things being equal. We can, therefore, conclude that labour market status influences SAH more at the top than at the bottom of the distribution.

To include fixed effects in the ordered logit estimation, we follow the suggestion of Ferrer-i-Carbonell and Frijters (2004). They show that an ordered logit model with fixed effects can be estimated as a fixed effect logit (conditional logit) model, where the ordered data are collapsed to binary data with individual-specific thresholds. In our case, the recording of observations to 'high' and 'low' health is individual-specific, based on the individuals' average health scores in the panel. In this case, only individuals with changes in health status over time can be included. Columns 5 and 6 of Table II show the estimation results. Again, the labour market status indicators that are time-invariant have been left out. The indicators for becoming unemployed or becoming employed are clearly not significant. ${ }^{12}$

As another way of taking fixed effects into account, we used Chamberlain's random effect estimation in an ordered probit model. The individual means of the control variables were included as additional explanatory variables to proxy the fixed effects and the model was estimated with random effect ordered probit. The estimates are shown in Column 7 of Table II. The results are fairly close to those obtained with ordered logit (Column 4). Those who are always unemployed in the data period or become unemployed at some stage have poorer health.

\subsection{Robustness analysis}

We have estimated several alternative models to investigate how robust our conclusions are. First, because of the small number of observations with low health status we tried combining health status groups 1 and 2 and used only four groups in the ordered logit analysis. However, the results were qualitatively similar to those obtained with five health groups and are not reported here. Secondly, we estimated the models (1) and (2), by using a continuous proxy for the discrete health scores. This was based on the observed shares of the scores (following Terza, 1987). The estimates using the converted scores (not reported in tables) were quite similar to the ones that were obtained treating the scores directly as cardinal measures of health.

Thirdly, we examined various ways of controlling for lagged health, as the descriptive analysis suggested that it may be worthwhile to include it as an explanatory variable. In addition, past health may have an impact on becoming unemployed, which can be controlled by including the lagged health variable in the regression. Table IV gives the results for various models with a lagged dependent variable. Column 1 shows the OLS estimates, where it is again assumed that health is a cardinal measure. The lagged health variable has a significant positive coefficient. Adding lagged health to the model reduces the significance of the indicators for the groups BU (becomes unemployed at least once) and AU (always unemployed). This is what one would expect, since if the individuals who experience unemployment have poor health in the first place, it should be picked up by the lagged variable. The lagged health variable has a positive coefficient of 0.535 . Therefore, deducting lagged health from both sides, changes in the health scores are negatively related to previous health. This is exactly what regression towards the mean implies: those with a high initial health level are likely to experience a fall in health and those with a low initial level a gain in health. ${ }^{13}$

Including fixed effects in the model with lagged health would lead to inconsistent estimates. We therefore use the Anderson-Hsiao estimator, where all the variables are differenced and the lagged

\footnotetext{
${ }^{12}$ Owing to poor convergence of the estimates, the age variable is left out of the estimation with control variables.

${ }^{13}$ The correlation between change in the health score and initial health can be positive only if the variance of the health scores increases over time (Campbell and Kenny, 1999).
} 
Table IV. Effect of labour market status and past health on SAH

\begin{tabular}{|c|c|c|c|c|c|}
\hline & OLS & First difference IV & Ordered logit & Ordered logit & RE ordered probit \\
\hline Becomes unemployed at least once (BU) & $\begin{array}{l}-0.047 \\
(0.024)^{*}\end{array}$ & & $\begin{array}{l}-0.264 \\
(0.084)^{* * *}\end{array}$ & $\begin{array}{r}-0.134 \\
(0.085)\end{array}$ & $\begin{array}{r}-0.084 \\
(0.064)\end{array}$ \\
\hline Unemployed after employment (UE) & $\begin{array}{c}0.020 \\
(0.036)\end{array}$ & $\begin{array}{c}0.032 \\
(0.027)\end{array}$ & $\begin{array}{c}-0.021 \\
(0.126)\end{array}$ & $\begin{array}{c}0.051 \\
(0.127)\end{array}$ & $\begin{array}{c}0.026 \\
(0.074)\end{array}$ \\
\hline Becomes employed at least once (BE) & $\begin{array}{c}0.033 \\
(0.026)\end{array}$ & & $\begin{array}{l}0.232 \\
(0.093)^{* * *}\end{array}$ & $\begin{array}{c}0.118 \\
(0.093)\end{array}$ & $\begin{array}{r}0.078 \\
(0.065\end{array}$ \\
\hline Employed after unemployment (EU) & $\begin{array}{r}-0.038 \\
(0.030)\end{array}$ & $\begin{array}{c}-0.008 \\
(0.024)\end{array}$ & $\begin{array}{c}-0.164 \\
(0.108)\end{array}$ & $\begin{array}{c}-0.147 \\
(0.108)\end{array}$ & $\begin{array}{c}-0.081 \\
(0.068)\end{array}$ \\
\hline Always unemployed (AU) & $\begin{array}{l}-0.120 \\
(0.028)^{* * *}\end{array}$ & & $\begin{array}{l}-0.615 \\
(0.092)^{* * *}\end{array}$ & $\begin{array}{l}-0.401 \\
(0.095)^{* * *}\end{array}$ & $\begin{array}{l}-0.234 \\
(0.070)^{* * *}\end{array}$ \\
\hline SAH $(t-1)$ & $\begin{array}{l}0.535 \\
(0.008)^{* * *}\end{array}$ & $\begin{array}{l}-0.437 \\
(0.011)^{* * *}\end{array}$ & & & \\
\hline $\mathrm{SAH}(t-1)=2$ & & & $\begin{array}{c}0.406 \\
(0.569)\end{array}$ & $\begin{array}{c}0.437 \\
(0.588)\end{array}$ & $\begin{array}{c}0.195 \\
(0.245)\end{array}$ \\
\hline $\mathrm{SAH}(t-1)=3$ & & & $\begin{array}{l}2.354 \\
(0.557)^{* * *}\end{array}$ & $\begin{array}{l}2.322 \\
(0.576)^{* * *}\end{array}$ & $\begin{array}{l}0.661 \\
(0.240)^{* * *}\end{array}$ \\
\hline $\mathrm{SAH}(t-1)=4$ & & & $\begin{array}{l}4.613 \\
(0.558)^{* * *}\end{array}$ & $\begin{array}{l}4.400 \\
(0.577)^{* * *}\end{array}$ & $\begin{array}{l}1.219 \\
(0.244)^{* * *}\end{array}$ \\
\hline $\mathrm{SAH}(t-1)=5$ & & & $\begin{array}{l}6.536 \\
(0.560)^{* * *}\end{array}$ & $\begin{array}{l}6.199 \\
(0.579)^{* * *}\end{array}$ & $\begin{array}{l}1.631 \\
(0.250)^{* * *}\end{array}$ \\
\hline Year dummies & Yes & Yes & Yes & Yes & Yes \\
\hline Control variables & Yes & Yes & No & Yes & Yes \\
\hline$N$ & 14524 & 6447 & 14524 & 14524 & 14524 \\
\hline
\end{tabular}

Note: Robust standard errors in parentheses (except in Columns 2 and 5). Significance: ${ }^{* * *} 1,{ }^{* *} 5,{ }^{*} 10 \%$. Reference group: continuously employed. Unreported control variables include age and its square, gender and the level of education in three categories. In the differenced models gender is excluded. In the RE model, individual means of control variables and first period values of lagged health categories are also included.

difference of the health score is instrumented with the lagged level of health two periods previously. In this case the differenced health obtains integer values between -4 and 4 (but we treat it as continuous variable). Again the indicators for changing the labour market status are non-significant (Table IV, Column 2). The negative sign of the lagged differenced health variable in these fixed effects results is consistent with regression towards the mean.

When the health variable is treated as an ordinal measure, we face an initial condition problem when the lagged health score is included. If the initial health status is treated as fixed, we can simply include lagged health in an ordered logit model. We do this by including separate dummy variables for different health scores in the previous period (denoted $\operatorname{SAH}(t-1)=j$, with $j=2, \ldots, 5$ ). The lagged values for levels 3-5 have significant coefficients (Table IV, Columns 3-4). Without observable individual characteristics the results are qualitatively similar to the OLS results. When the personal characteristics are included, only the indicator for being always unemployed is significant. The marginal effects show that a high level of the health score in the past has a very strong effect on the probability of good health (Column 6 in Table III). A person who had health level 5 in the previous year has $91 \%$ higher probability of having health level 5 in the current year than a person who had health level 1 in the past period. Even those who previously had health level 3 have $37 \%$ higher probability of having health level 5 than those who had poorest health. These effects are much larger than the ones that stem from the labour market status.

When the initial condition is treated as stochastic we use the Chamberlain type of approach and include the individual means of the characteristics (to proxy fixed effects) and the initial levels of the lagged health status dummies (to account for the initial condition) in a random effect ordered probit estimation (see Wooldridge, 2002). The results shown in Column 5 of Table IV are qualitatively similar to the ordered logit estimates, although the magnitudes of the coefficients are somewhat different. 


\subsection{Propensity score matching estimates}

To evaluate the robustness of the basic results that are based on regression-based models further, we estimate propensity score matching models. ${ }^{14}$ Persons with certain observable characteristics are much more likely to be unemployed. For instance, the less educated face disproportionate difficulties in the labour market. The key idea of propensity score matching is to construct a control group from the group of untreated individuals and to ensure that the control group is as similar as possible to the treatment group with respect to the available observable characteristics. In our case, the treatment is becoming unemployed (or becoming employed) and we study its effect on SAH. In particular, we need not worry about the endogeneity of becoming unemployed (or becoming employed).

Matching has some important advantages over regression-based methods that were used to produce the basic results. Being a non-parametric method, matching does not impose any specific linearity assumptions on the evaluated effects that are inherent in regression-based modelling. Furthermore, matching explicitly tries to find for each untreated unit a similar treated unit to evaluate the counterfactual, i.e. what would happen to the treatment group without the treatment. As a drawback, it has to be assumed that there are no unobservable factors that affect the individuals' probability of becoming unemployed. Controlling for the observable factors, the outcome (health) is assumed to be independent of the treatment status (conditional independence or unconfoundedness assumption). One need not control for all the observable factors at the same time, but it suffices to condition on the propensity score, i.e. the probability of treatment. In using the propensity score, one has to further rule out the perfect predictability of the treatment (overlap or common support assumption). Corresponding assumptions apply when the treatment is becoming employed.

We first estimate a probit model for the probability of becoming unemployed (i.e. the probability that the person is unemployed, given that he or she was employed in the previous year). The explanatory variables include personal factors such as age, age squared and the level of education (dummies for medium and high levels). We also include the employer's characteristics, a dummy for small firms (fewer than 20 employees) and a dummy for the public sector. These variables are lagged by one period. In addition, we include lagged health status and year dummies. For simplicity, we include the lagged health score directly, rather than separate dummies for different health levels. The probit model is estimated by using pooled data for the whole period. Since the aim is to model selection on observables, we do not model unobservable individual characteristics in the probit model. The data set in the probit estimation consists of year pairs for those who are employed both in the current year and in the previous year and those who are unemployed in the current year, but were employed in the previous year.

The propensity scores are used with nearest-neighbour matching (one-to-one matching with replacement) and kernel (Epanechnikov kernel) methods when calculating the average treatment effect on the treated (ATT). ${ }^{15}$ In particular, the SAH status of those that have become unemployed, i.e. the treatment group, is compared with those employed who have a similar propensity to be in the pool of unemployed persons, but are not currently in that pool, i.e. the control group. Assuming that the health status is a cardinal outcome measure, we then calculate the ATT. An alternative measure of health impact, which takes better account of the ordinal nature of SAH, is constructed using the probabilities of different levels of health. Using the same set of individuals as in the probit model, we estimate an ordered probit model for the health level using pooled data over the period 1996-2001, with age, age squared, gender, educational levels and lagged health as the explanatory variables. Using these estimates, we calculate the predicted probabilities of all five health levels for each individual. Using these

\footnotetext{
${ }^{14}$ See, for example, Blundell and Costa Dias (2000), Lee (2005), and Caliendo and Kopeinig (2008) for surveys of the matching methods.

${ }^{15}$ In our analysis we use the programs written by Becker and Ichino (2002), and Leuven and Sianesi (2006) for Stata.
} 
Table V. Probit models for change in labour market status

\begin{tabular}{lcc}
\hline & Becomes unemployed & Becomes employed \\
\hline Age & -0.074 & 0.158 \\
& $(0.016)^{* * *}$ & $(0.025)^{* * *}$ \\
Age squared & 0.001 & -0.002 \\
& $(0.0002)^{* * *}$ & $(0.0003)^{* * *}$ \\
Middle education $(t-1)$ & -0.186 & 0.196 \\
& $(0.057)^{* * *}$ & $(0.087)^{* * *}$ \\
Higher education $(t-1)$ & -0.507 & 0.438 \\
& $(0.065)^{* * *}$ & $(0.109)^{* * *}$ \\
Small firm $(t-1)$ & 0.408 & \\
& $(0.046)^{* * *}$ & \\
Public sector $(t-1)$ & 0.080 & 0.178 \\
SAH $(t-1)$ & $(0.048)^{*}$ & $(0.051)^{* * *}$ \\
Year dummies & -0.062 & Yes \\
$N$ & $(0.034)^{* *}$ & 1353 \\
\hline Note: Standard errors in parentheses. Significance: & \\
& Yes $1,{ }^{* *} 5,{ }^{*} 10 \%$. &
\end{tabular}

probabilities we obtain the expected health score $E(\mathrm{SAH})=\sum_{j=1}^{5} j \operatorname{Pr}(\mathrm{SAH}=j)$. This is then used as the outcome in propensity score matching. ${ }^{16}$

The above measures essentially treat the data as separate cross-sections and compare the health status of the treated and controls in each year. As an alternative, we utilize the panel aspect and use changes in health scores or expected health scores as the outcome measures, i.e. we use difference-indifferences matching (e.g. Blundell and Costa Dias, 2000).

The first column of Table $\mathrm{V}$ shows the estimates of the probit model for becoming unemployed. As expected, higher education decreases the probability of becoming unemployed, other things being equal, and employees in small firms are more likely to become unemployed. The age effect is U-shaped with young and old employees more likely to become unemployed; the minimum is at the age of 43 . Public sector employees are more likely to face unemployment, which may be related to a large share of temporary employees in this sector. In addition, lagged SAH in the previous year has a negative and significant coefficient when explaining the probability of becoming unemployed in the current year.

Propensity score matching is performed using the region of common support for the propensity scores, which included 405 cases of a person becoming unemployed (none off support) and 11006 control cases. ${ }^{17}$ Figure 2 (left-hand panel) plots the distributions of the propensity scores before matching. The figure shows that for the controls the probability of becoming unemployed tends to be smaller. To check the validity of the matching, covariate balancing is tested. The results are shown in Table VI. For all the variables matching succeeds in making the means of the covariates close to each other for the treated and controls. ${ }^{18}$

\footnotetext{
${ }^{16}$ We have to treat the results with this outcome measure with some caution, since the basic assumptions of propensity score matching need not carry over to this kind of nonlinear outcomes. For the probability of a binary outcome one could use the adjustment based in inverse probability functions, suggested by Blundell et al. (2004). This is not possible in our case, as the expected health involves several probabilities.

${ }^{17}$ We follow the definition of common support in the Leuven-Sianesi program, where this is defined to include all controls and those treated whose propensity score is below the maximum or above the minimum propensity score of the controls. In the Becker-Ichino program the common support option keeps all treated and those controls with a propensity score below the maximum or above the minimum of that of the treated. In practice, there are small differences in the results, but the significance of the estimated ATTs is not affected.

${ }^{18}$ If the data are divided into seven blocks (based on an algorithm; see Becker and Ichino, 2002), the balancing property holds in all of the blocks.
} 

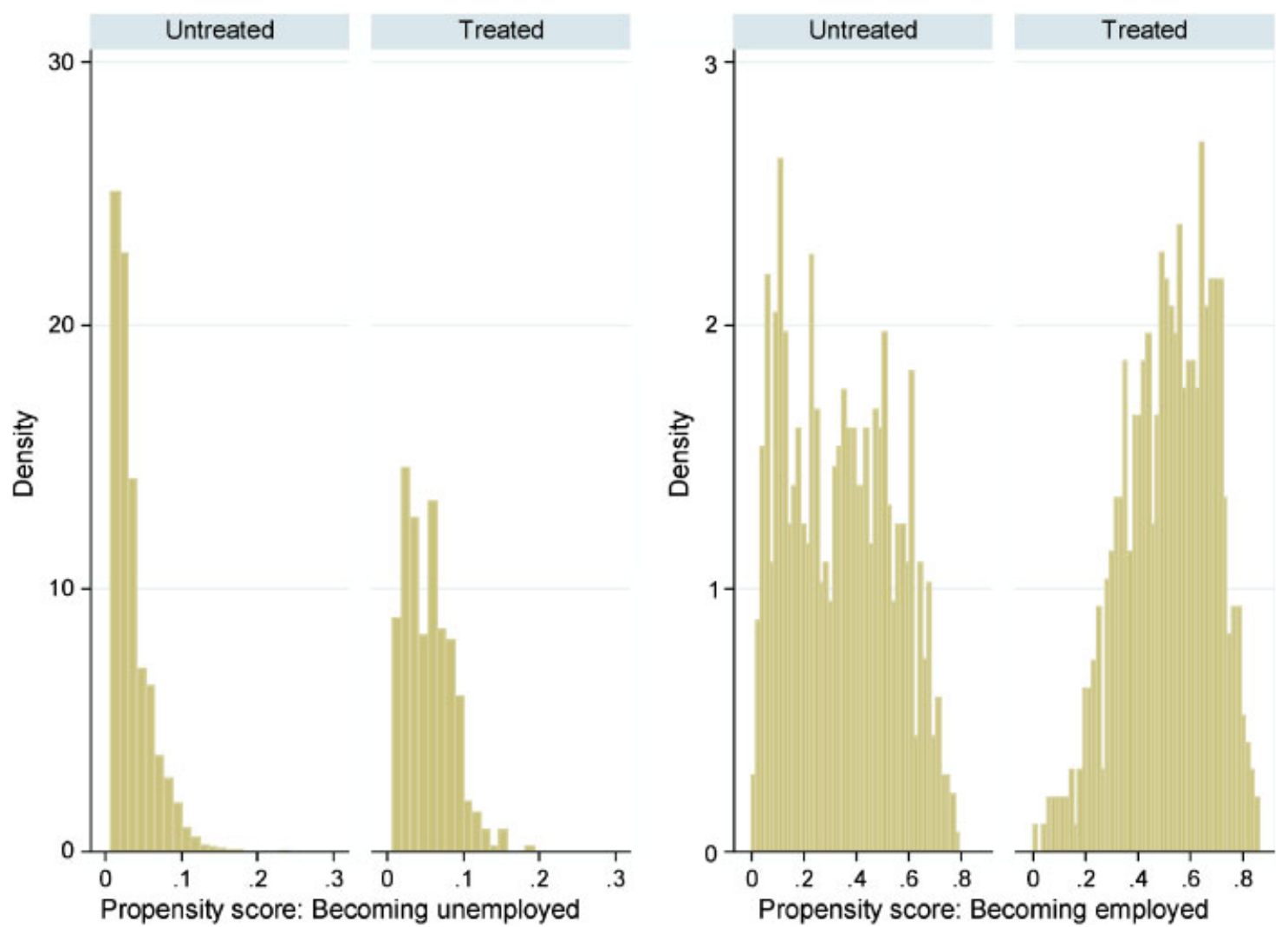

Figure 2. Distribution of propensity scores of becoming unemployed and becoming employed in the region of common support

Table VII reports the estimated treatment effects on the treated, with standard errors computed by bootstrapping. When nearest-neighbour matching with replacement is used, the average treatment effect of becoming unemployed on SAH is small and not statistically significant. The same result is obtained when expected health is the outcome. As a robustness check, nearest-neighbour matching was also conducted for each year separately. Although the results slightly varied over time, all of the estimated ATTs were non-significant. (The results are not reported in the table.) To check the robustness of the result further, kernel matching is also used. Now there is a significant effect, when expected health is the outcome. Unemployment causes a somewhat lower expected health level according to kernel matching.

However, a closer way to compare the matching results with those obtained with simple parametric regression methods (difference-in-differences) is to use the change in health as the outcome. Now both nearest-neighbour and kernel matching give the same conclusion: changes in health or expected health are not statistically significantly different in the treatment group and control group. ${ }^{19}$ All in all, the results based on matching confirm our earlier conclusions that the experience of unemployment as such

\footnotetext{
${ }^{19}$ When change in expected health is used as the outcome, the number of observations in matching is smaller than in the other cases. In the estimation of the ordered probit models for health we use lagged health as an explanatory variable, so we lose 1 year and in differencing we lose another year. We have 287 treated and 7773 controls in the region of common support (no treated off support).
} 
Table VI. Test of covariate balancing for becoming unemployed

\begin{tabular}{|c|c|c|c|c|c|c|}
\hline Variable & Sample & Mean treated & Mean control & $\%$ bias & $\%$ reduction of bias & $t$-Test \\
\hline \multirow[t]{2}{*}{ Age } & Unmatched & 42.541 & 42.306 & 2.2 & & 0.47 \\
\hline & Matched & 42.541 & 42.849 & -2.9 & -31.6 & -0.38 \\
\hline \multirow[t]{2}{*}{ Age squared } & Unmatched & 1938.2 & 1886.1 & 5.9 & & 1.24 \\
\hline & Matched & 1938.2 & 1968.9 & -3.5 & 40.8 & -0.46 \\
\hline \multirow[t]{2}{*}{ Middle education $(t-1)$} & Unmatched & 0.467 & 0.393 & 14.8 & & $2.96^{* * *}$ \\
\hline & Matched & 0.467 & 0.481 & -3.0 & 79.8 & -0.42 \\
\hline \multirow[t]{2}{*}{ Higher education $(t-1)$} & Unmatched & 0.217 & 0.434 & -47.4 & & $-8.67^{* * *}$ \\
\hline & Matched & 0.217 & 0.207 & 2.2 & 95.4 & 0.34 \\
\hline \multirow[t]{2}{*}{ Small firm $(t-1)$} & Unmatched & 0.588 & 0.351 & 48.8 & & $9.79^{* * *}$ \\
\hline & Matched & 0.588 & 0.585 & 0.5 & 99.0 & 0.07 \\
\hline \multirow[t]{2}{*}{ Public sector $(t-1)$} & Unmatched & 0.427 & 0.449 & -4.3 & & -0.85 \\
\hline & Matched & 0.427 & 0.373 & 10.9 & -153.7 & 1.58 \\
\hline \multirow[t]{2}{*}{$\mathrm{SAH}(t-1)$} & Unmatched & 3.842 & 3.965 & -16.9 & & $-3.40^{* * *}$ \\
\hline & Matched & 3.842 & 3.857 & -2.0 & 88.0 & -0.29 \\
\hline
\end{tabular}

Note: Year dummies not reported. Significance: ${ }^{* * *} 1,{ }^{* *} 5,{ }^{*} 10 \%$.

Table VII. Average treatment effect on the treated for overall unemployment

\begin{tabular}{|c|c|c|c|c|c|}
\hline \multirow[b]{2}{*}{ Treatment } & \multirow[b]{2}{*}{ Matching method } & \multicolumn{4}{|c|}{ Outcome } \\
\hline & & SAH & $E(\mathrm{SAH})$ & Change in SAH & Change in $E(\mathrm{SAH})$ \\
\hline \multirow[t]{4}{*}{ Becomes unemployed } & Nearest-neighbour & 0.006 & -0.008 & 0.020 & 0.015 \\
\hline & & $(0.046)$ & $(0.018)$ & $(0.045)$ & $(0.030)$ \\
\hline & Kernel & -0.061 & -0.059 & 0.014 & -0.001 \\
\hline & & $(0.047)$ & $(0.017)^{* *}$ & $(0.044)$ & $(0.030)$ \\
\hline \multirow{4}{*}{ Becomes employed } & Nearest-neighbour & 0.061 & 0.004 & 0.037 & -0.003 \\
\hline & & $(0.032)^{*}$ & $(0.008)$ & $(0.034)$ & $(0.019)$ \\
\hline & Kernel & 0.030 & 0.009 & 0.008 & 0.009 \\
\hline & & $(0.031)$ & $(0.007)$ & $(0.032)$ & $(0.021)$ \\
\hline
\end{tabular}

Note: Bootstrap standard errors (150 replications) in parentheses. Significance: ${ }^{* * * *} 1,{ }^{* *} 5,{ }^{*} 10 \%$.

does not have an independent influence on SAH, but those persons with a low perception of their health are more likely to become unemployed in the first place. In fact, it is likely that using the health level as the outcome picks up the health difference, even when lagged health is used as a variable in the estimation of the propensity scores.

A corresponding matching analysis is done for the treatment of becoming employed. In this case the data set is restricted in each year pair to those who are unemployed in both the current and past periods and those who become employed in the current period. The second column of Table V shows the estimates from the probit models for becoming employed. Age has an inverted U-shaped relationship with the probability of becoming employed, with the maximum at the age of 35, and higher education increases the employment probability. In addition, SAH in the previous year has a positive and significant coefficient. Note that because all the individuals in this analysis are unemployed in $t-1$, information about the employer is not available.

Propensity score matching is performed using the region of common support for the scores, which includes 542 treated (18 off support) and 793 controls. Figure 2 (right-hand panel) shows the distribution of the propensity scores for the treated and controls. The treatment group tends to have a higher probability of becoming employed, which is understandable, since the control group also includes those who are unemployed for the whole data period 1996-2001. To check the validity of the 
Table VIII. Test of covariate balancing for becoming employed

\begin{tabular}{llccccc}
\hline Variable & Sample & Mean treated & Mean control & \% bias & \% reduction of bias & $t$-Test \\
\hline Age & Unmatched & 37.929 & 44.889 & -60.9 & & $-10.89^{* * *}$ \\
& Matched & 38.094 & 37.738 & 3.1 & 94.9 & 0.56 \\
Age squared & Unmatched & 1549.4 & 2165.2 & -66.1 & & $-11.72^{* * *}$ \\
& Matched & 1564.5 & 1529.3 & 3.8 & 94.3 & 0.72 \\
Middle education $(t-1)$ & Unmatched & 0.504 & 0.393 & 22.3 & & $4.04^{* * *}$ \\
& Matched & 0.517 & 0.526 & -1.9 & 91.6 & -0.30 \\
Higher education $(t-1)$ & Unmatched & 0.239 & 0.137 & 26.2 & & $4.84^{* * *}$ \\
SAH $(t-1)$ & Matched & 0.218 & 0.216 & 0.5 & 98.2 & 0.07 \\
& Unmatched & 4.016 & 3.653 & 45.8 & & $8.19^{* * *}$ \\
& Matched & 3.993 & 3.969 & 3.0 & 93.4 & 0.52 \\
\hline
\end{tabular}

Note: Year dummies not reported. Significance: ${ }^{* * *} 1,{ }^{* *} 5,{ }^{*} 10 \%$.

matching, covariate balancing is tested. According to Table VIII, the matching again succeeds in making the distributions of the covariates similar. ${ }^{20}$

The lower part of Table VII reports the results. When nearest-neighbour matching is used, the average treatment effect of becoming employed is 0.061 , which is statistically significant at the $10 \%$ level. The ATTs with expected health as the outcome or the ones from kernel matching are not significant. ${ }^{21}$ When we use change in health as the outcome, we again obtain the result that becoming employed does not improve health in a statistically significant way. This is consistent with our findings using difference-in-differences models. As a robustness check, we re-run the nearest-neighbour matching analyses for each year separately. (The results are not reported in the table.) The conclusions were, otherwise, similar to those obtained with the pooled data, but with health as the outcome ATT was 0.360 and significant at the $1 \%$ level ( $t$-value 8.55 ) in 2000 , driving the result for the pooled data.

\subsection{Accounting for the heterogeneity in unemployment}

It is worthwhile to look at possible sources of heterogeneity in the relationship between unemployment and health. In the above analysis we have treated all kinds of unemployment in the same way. Now we examine whether the definition of 'experiencing unemployment' matters for the robustness of the basic results. In this case, we define long-term unemployment as the relevant measure of unemployment experience. ${ }^{22}$ The long-term unemployed are those persons who have been unemployed continuously for at least 6 months. The share of the long-term unemployed of all unemployed persons in the data set is $45 \%$ (Table I). The median duration of unemployment is 4 months, conditional on being unemployed currently. Because selection by observable characteristics such as education is arguably more important in the case of long-term unemployment than for overall unemployment, we focus on the results from the matching models.

We drop the short-term unemployed from matching. Hence, we compare the health level of the longterm unemployed with the health of those who are continuously employed. The treatment is in this case being long-term unemployed conditionally on having been employed in the previous period, and the outcome variable is alternatively health, expected health or changes in them. The probit models for

\footnotetext{
${ }^{20}$ When the data are divided into six blocks, the balancing holds in all other cases, except for the age variable in the first block (lowest end of the distribution of propensity scores). If the squared age is left out, the balancing property holds. We have kept squared age in the model, but examined the sensitivity of the results to its exclusion. This has practically no effect on the estimated treatment effects.

${ }^{21}$ Again, the number of observations is slightly smaller when we have change in expected health as the outcome. There are 353 treated (17 off support) and 413 controls on common support.

${ }^{22}$ For example, Gordo (2006) discovers, using the GSOEP data with random effects models, that being unemployed for a long period of time has a significant negative effect on health satisfaction while short-term unemployment does not always cause negative effects.
} 
Table IX. Average treatment effect on the treated for long-term unemployment

\begin{tabular}{|c|c|c|c|c|c|}
\hline \multirow[b]{2}{*}{ Treatment } & \multirow[b]{2}{*}{ Matching method } & \multicolumn{4}{|c|}{ Outcome } \\
\hline & & SAH & $E(\mathrm{SAH})$ & Change in SAH & Change in $E(\mathrm{SAH})$ \\
\hline \multirow[t]{2}{*}{ Becomes long-term unemployed } & Nearest-neighbour & $\begin{array}{l}-0.156 \\
(0.081)^{*}\end{array}$ & $\begin{array}{r}-0.034 \\
(0.031)\end{array}$ & $\begin{array}{r}-0.099 \\
(0.080)\end{array}$ & $\begin{array}{l}0.105 \\
(0.055)^{*}\end{array}$ \\
\hline & Kernel & $\begin{array}{l}-0.273 \\
(0.085)^{* *}\end{array}$ & $\begin{array}{l}-0.154 \\
(0.030)^{* *}\end{array}$ & $\begin{array}{r}-0.084 \\
(0.088)\end{array}$ & $\begin{array}{c}0.028 \\
(0.055)\end{array}$ \\
\hline \multirow{2}{*}{$\begin{array}{l}\text { Becomes employed after long-term } \\
\text { unemployment }\end{array}$} & Nearest-neighbour & 0.154 & 0.025 & 0.109 & -0.039 \\
\hline & Kernel & $\begin{array}{c}(0.054)^{* *} \\
0.057 \\
(0.055)\end{array}$ & $\begin{array}{c}(0.014)^{*} \\
-0.011 \\
(0.013)\end{array}$ & $\begin{array}{c}(0.057)^{*} \\
0.074 \\
(0.055)\end{array}$ & $\begin{array}{c}(0.036) \\
0.000 \\
(0.032)\end{array}$ \\
\hline
\end{tabular}

Note: Bootstrap standard errors (150 replications) in parentheses. Significance: ${ }^{* * *} 1,{ }^{* *} 5,{ }^{*} 10 \%$.

becoming long-term unemployed contain the same explanatory variables as earlier for all unemployed. As expected, persons with a low perception of their health are more likely to become long-term unemployed. A corresponding analysis is done for the treatment of becoming employed after experiencing long-term unemployment.

Table IX summarizes the results. When nearest-neighbor matching is used with the health level as the outcome variable, the average treatment effect of becoming long-term unemployed is -0.16 . The effect is statistically significant at the $10 \%$ level. Accordingly, there is some evidence that becoming long-term unemployed leads to a deterioration in SAH. However, the results differ by using different measures of health, i.e. health vs expected health and health level vs change, and between different matching methods, nearest-neighbour vs kernel matching. Additionally, becoming employed after long-term unemployment improves SAH in a statistically significant way when we use nearest-neighbour matching, but not with kernel matching. The result on health is weaker when the panel dimension of the data is taken into account in difference-in-differences matching.

We have also explored the relationship between unemployment and health by gender and age. We briefly comment on the results without presenting them in tables. Economou et al. (2007) show that the effect of past unemployment spells on health is significant for the younger age group, whereas the effect does not prevail for the older group. We have used the same age groups as they have, dividing the workers into two groups (those aged less than 45 years old and those aged 45 years or more). Our results are almost similar for both genders. However, there is some evidence according to which unemployment has a negative effect on health among workers aged less than 45 years. This is consistent with the findings in Economou et al. (2007). They argue that the pattern emerges, because those who are approaching retirement are able to cope better with unemployment compared with the younger workers who will be staying longer in the labour force.

Furthermore, we have considered the robustness of our results with respect to alternative measures of health. There are two questions in the ECHP that also cover mental aspects of health. There is the question (PH003A): 'Are you hampered in your daily activities by any physical or mental health problem, illness or disability'?. Economou et al. (2007) use this particular question. Moreover, there is another question (PH005): 'During the past two weeks, have you had to cut down things you usually do about the house, at work or in your free time because of an emotional or mental health problem'?. The responses to the questions can be rescaled to a binary response of 0 indicating the total absence of health problems and 1 otherwise. The averages over the period 1996-2001 for these two health indicators are 26 and $2 \%$, respectively. Overall, the earlier conclusions remain the same. Therefore, it is hard to detect negative effects of unemployment on these health indicators that also cover mental aspects of health. 


\section{CONCLUSIONS}

We have explored the relationship between unemployment and SAH. The most important finding of this paper is that the event of unemployment does not matter as such for the level of SAH, when evaluated in a panel data setting, since the health status of those who end up being unemployed is already lower than that of the continually employed before their unemployment episodes actually start. The matching results are similar to those obtained with simple parametric regression methods (difference-in-differences models) when the change in health is used as the outcome.

Therefore, persons who have poor $\mathrm{SAH}$, for some reason or another, are being selected for the pool of the unemployed. This explains why, in a cross-section, unemployment is associated with poor SAH. Accordingly, unemployment may merely be a veil that hides the underlying causes of poor SAH. We discover that the definition of 'experiencing unemployment' matters somewhat for the findings. In particular, we are more likely to obtain negative effects of unemployment on health when we use longterm unemployment as the relevant measure of unemployment experience.

The Finnish results are interesting in the context of the earlier studies. Ahn et al. (2004) report smaller effects of unemployment on satisfaction with the main activity in Denmark and the Netherlands than in other EU countries. They provide cross-country evidence according to which this pattern emerges, because the unemployment rate is lower, the spells are shorter and unemployment protection (unemployment benefits and active labour market policies) is greater in these two countries. In this respect, the Finnish results demonstrate that high unemployment may also dilute the negative effects of unemployment on SAH. This conclusion is in accordance with the findings in Clark (2003). Regarding the generalizability of the Finnish results it is important to note that unemployment decreased quite close to the general European level towards the end of the observation period (e.g. Koskela and Uusitalo, 2006). Moreover, according to OECD (2006), the net replacement rate of unemployment benefits that may have an influence on the effect of unemployment on $\mathrm{SAH}$, as argued by Ahn et al. (2004), does not differ much in Finland from the central western European standard.

Our basic finding, according to which unemployment does not appear to have a significant negative effect on SAH, is consistent with the results reported by Browning et al. (2006). They discover that being displaced does not cause hospitalization for stress-related disease in Denmark. ${ }^{23}$ Our results are also in line with those by Lucas et al. (2004) for unemployment and life satisfaction. They show that individuals tend to shift back towards their baseline levels of life satisfaction after unemployment has lasted for some time. The pattern demonstrates that the unemployed become mentally accustomed to their situation rather quickly. This may arise because unemployment has fewer stigma effects in the presence of high aggregate unemployment.

From the policy perspective, the findings of this paper suggest that the allocation of resources to improve the health status of those that are currently unemployed is not enough. It is equally important to put resources into the improvement of health of those persons currently employed, but who are more likely to experience unemployment at some point of time.

\section{ACKNOWLEDGEMENTS}

Earlier versions of this paper were presented at the UNU-WIDER Conference on Advancing Health Equality, Helsinki and at the Conference on Unemployment and Labour Market Policies, Nürnberg. We are grateful to the seminar audiences for discussion. We would like to thank two anonymous referees and Jennifer Roberts (associate editor) for valuable comments that have greatly improved the

\footnotetext{
${ }^{23}$ They use a random $10 \%$ sample of the male population of Denmark for the years 1981-1999.
} 
paper. Furthermore, we are grateful to Eija Savaja for her help with the data. The usual disclaimer applies.

\section{REFERENCES}

Ahn A, Garcia JR, Jimeno JF. 2004. The impact of unemployment on individual well-being in the EU. Working Paper No. 29, European Network of Economic Policy Research Institutes.

Arrow JO. 1996. Estimating the influence of health as a risk factor on unemployment: a survival analysis of employment durations for workers surveyed in the German Socio-Economic Panel (1984-1990). Social Science and Medicine 42: 1651-1659.

Becker SO, Ichino A. 2002. Estimation of average treatment effects based on propensity scores. The Stata Journal 2: $358-377$.

Björklund A. 1985. Unemployment and mental health. Journal of Human Resources 20: 469-483.

Björklund A, Eriksson T. 1998. Unemployment and mental health: evidence from research in Nordic countries. Scandinavian Journal of Social Welfare 7: 219-235.

Blundell R, Costa Dias M. 2000. Evaluation methods for non-experimental data. Fiscal Studies 21: 427-468.

Blundell R, Costa Dias M, Meghir C, Van Reenen J. 2004. Evaluating the employment impact of a mandatory job search program. Journal of the European Economic Association 2: 569-606.

Böckerman P, Ilmakunnas P. 2006. Elusive effects of unemployment on happiness. Social Indicators Research 79: 159-169.

Browning M, Moller Dano A, Heinesen E. 2006. Job displacement and stress-related health outcomes. Health Economics 15: 1061-1075.

Caliendo M, Kopeinig S. 2008. Some practical guidance for the implementation of propensity score matching. Journal of Economic Surveys 22: 31-72.

Campbell DT, Kenny DA. 1999. A Primer on Regression Artifacts. Guildford Press: New York and London.

Cantarero D, Pascual M. 2005. Socio-economic status and health: evidence from the ECHP. Economics Bulletin 9: $1-17$.

Clark A. 2003. Unemployment as a social norm: psychological evidence from panel data. Journal of Labor Economics 21: 323-351.

Clark A. 2007. A note on unhappiness and unemployment duration. Applied Economics Quarterly 52: 291-308.

Clark A, Diener E, Georgellis Y, Lucas R. 2008. Lags and leads in life satisfaction: a test of the baseline hypothesis. Economic Journal 118: F222-F243.

Clark A, Oswald AJ. 1994. Unhappiness and unemployment. Economic Journal 104: 648-659.

Crossley TF, Kennedy S. 2002. The reliability of self-assessed health status. Journal of Health Economics 21: 643-658.

Di Tella R, MacCulloch RJ, Oswald AJ. 2001. Preferences over inflation and unemployment: evidence from surveys of happiness. The American Economic Review 91: 335-341.

Economou A, Nikolaou A, Theodossiou I. 2007. Past unemployment experience and health status. Discussion Paper No. 16, Centre for European Labour Market Research.

Ervasti H, Venetoklis T. 2006. Unemployment and subjective well-being: does money make a difference? Discussion Paper No. 391, Government Institute for Economic Research.

Etienne J-M, Skalli A, Theodossiou I. 2007. Do economic inequalities harm health? Evidence from Europe. Discussion Paper No. 13, Centre for European Labour Market Research.

Ferrer-i-Carbonell A, Frijters P. 2004. How important is methodology for the estimates of the determinants of happiness? Economic Journal 114: 641-659.

Franks P, Gold MR, Fiscella K. 2003. Sociodemographics, self-rated health, and mortality in the US. Social Science and Medicine 56: 2505-2514.

Gordo LR. 2006. Effects of short- and long-term unemployment on health satisfaction: evidence from German data. Applied Economics 38: 2335-2350.

Henning C, Müllensiefen D, Bargmann J. 2003. Comparison of changes in a pretest-posttest design with Likert scales. Research Report No. 118, Seminar für Statistik, ETH.

Hildebrand V, Van Kerm P. 2005. Income inequality and self-rated health status: evidence from the European Community Household Panel. Working Paper No. 01, IRISS.

Idler EL, Benyamini Y. 1997. Self-rated health and mortality: a review of twenty-seven community studies. Journal of Health and Social Behaviour 38: 21-37. 
Jäntti M, Martikainen P, Valkonen T. 2000. When the welfare state works: unemployment and mortality in Finland. In The Mortality Crisis in Transitional Economies, Cornia AG, Paniccia R (eds). Oxford University Press: Oxford.

Koskela E, Uusitalo R. 2006. The un-intended convergence: how the Finnish unemployment reached the European level. In Structural Unemployment in Europe: Reasons and Remedies, Werding M (ed.). The MIT Press: Cambridge, MA.

Kristensen N, Johansson E. 2008. New evidence on cross-country differences in job satisfaction using anchoring vignettes. Labour Economics 15: 96-117.

Kuhn A, Lalive R, Zweimüller J. 2004. Does unemployment make you sick? University of Zurich, Mimeo.

Lahelma E. 1989. Unemployment, re-employment and mental well-being: a panel survey of industrial jobseekers in Finland. Scandinavian Journal of Social Medicine 43(Suppl): 1-170.

Lahelma E, Rahkonen O, Huuhka M. 1997. Changes in the social patterning of health? The case of Finland 1986-1994. Social Science and Medicine 44: 789-799.

Lee M-J. 2005. Micro-Econometrics for Policy, Program, and Treatment Effects. Oxford University Press: Oxford.

Leino-Arjas P, Liira J, Mutanen P, Malmivaara A, Matikainen E. 1999. Predictors and consequences of unemployment among construction workers: prospective cohort study. British Medical Journal 319: 600-605.

Leuven E, Sianesi B. 2006. PSMATCH2: Stata Module to Perform Full Mahalanobis and Propensity Score Matching, Common Support Graphing, and Covariate Imbalance Testing. Boston College Department of Economics, Statistical Software Components No. S432001.

Lindbeck A, Nyberg S, Weibull JW. 1999. Social norms and economic incentives in the welfare state. Quarterly Journal of Economics 114: 1-35.

Lucas RE, Clark AE, Georgellis Y, Diener E. 2004. Unemployment alters the set point for life satisfaction. Psychological Science 15: 8-13.

Martikainen P. 1995. Socioeconomic mortality differentials in men and women according to own and spouse's characteristics in Finland. Sociology of Health \& Illness 17: 353-375.

Martikainen P, Mäki N, Jäntti M. 2007. The effects of unemployment on mortality following workplace downsizing and workplace closure: a register-based follow-up study of Finnish men and women during economic boom and recession. American Journal of Epidemiology 165: 1070-1075.

Martikainen P, Valkonen T. 1996. Excess mortality of unemployed men and women during a period of rapidly increasing unemployment. Lancet 348: 208-213.

Mathers CM, Schofield DJ. 1998. The health consequences of unemployment: the evidence. The Medical Journal of Australia 168: 178-182.

McFadden DL, Bemmaor AC, Caro FG, Dominitz J, Jun BH, Lewbel A, Matzkin RL, Molinari F, Schwarz N, Willis RJ, Winter JK. 2005. Statistical analysis of choice experiments and surveys. Marketing Letters 16: $183-196$.

Nyman J. 2002. Does Unemployment Contribute to Ill-being: Results from a Panel Study Among Adult Finns, 1989/90 and 1997. National Health Institute, A4/2002.

OECD 2006. OECD Employment Outlook. OECD, Paris.

Peracchi F. 2002. The ECHP: a review. Empirical Economics 27: 63-90.

Riphahn RT. 1999. Income and employment effects of health shocks: a test case for the German welfare state. Journal of Population Economics 12: 363-389.

Terza JV. 1987. Estimating linear models with ordinal qualitative regressors. Journal of Econometrics 34: 275-291.

Van Doorslaer E, Jones A. 2003. Inequalities in self-reported health: validation of a new approach to measurement. Journal of Health Economics 22: 61-78.

Wooldridge JM. 2002. Econometric Analysis of Cross Section and Panel Data. The MIT Press: Cambridge, MA. 